\title{
Letter to the editor regarding the article "The use of Psychiatric Electroencephalography Evaluations Registry (PEER) to personalize pharmacotherapy"
}

This article was published in the following Dove Press journal:

Neuropsychiatric Disease and Treatment

4 October 2017

Number of times this article has been viewed

\section{Peter JWeina'}

Sanjur Brooks ${ }^{2}$

'Department of Research Programs, Infectious Diseases Physician, WRNMMC and $\mathrm{FBCH}$, Medicine and Preventive Medicine, USUHS, Walter Reed National Military Medical Center, Rockville Pike, Bethesda, MD, USA; 'Department of Research Programs, Walter Reed National Military Medical Center, Rockville Pike, Bethesda, MD, USA
Correspondence: Peter J Weina Department of Research Programs, Infectious Diseases Physician, WRNMMC and $\mathrm{FBCH}$, Medicine and Preventive Medicine, USUHS, Walter Reed National Military Medical Center, Rockville Pike, Bethesda, MD, USA

Email peter.j.weina.mil@mail.mil

\section{Dear editor}

We read the paper of Iosifescu et al, "The use of Psychiatric Electroencephalography Evaluations Registry (PEER) to personalize pharmacotherapy”, with great apprehension. The authors' description of the study's limitations was gravely understated. Under the "Study limitations" section, the authors stated "The Walter Reed PEER Trial has certain limitations that should be kept in mind when interpreting the study findings". However, the authors fail to address the study's regulatory challenges and ethical concerns of the Institutional Review Board (IRB) at Walter Reed National Military Medical Center (WRNMMC).

In May 2014, the IRB suspended "A prospective, double blind, randomized, multicenter study to evaluate the utility, safety, and efficacy of using PEER Interactive to inform the prescription of medications to patients with a primary diagnosis of a depressive disorder and comorbidity of non-psychotic behavioral disorders versus treatment as usual" study until further enquiry occurred. The suspension of the study stemmed from the concern of the IRB for participants' safety and regulatory noncompliance. Also, there was a concern that the participants in the trial were unduly influenced and/or inappropriately consented to participate.

After a 6-month enquiry into the study, the research team of the study did not present sufficient evidence that mitigated the concerns of the IRB. Hence, the WRNMMC IRB disapproved the request from the principal investigator to reinstate this study, which was stated in the IRB disapproval letter dated January 30, 2015.

In addition to the disapproval, the IRB mandated all data collected at WRNMMC not to be used for publications, research justification or for analysis for future clinical trials. The IRB also requested that all publications and/or presentations referencing the study's data from WRNMMC be rescinded. These requests were communicated to the sponsor at the time of the IRB disapproval and sanctions on the results.

The authors of the article also stated, "a full on-site Food and Drug Administration (FDA) inspection of the PEER Interactive Trial was conducted in February 2016, and revealed no significant concerns". ${ }^{1}$ This statement is misleading. It is a misrepresentation of the institution involved and the scope of the FDA audit. No such FDA inspection occurred at WRNMMC; in February 2016, the FDA conducted an audit at another military research institute with a similar name (the Walter Reed Army Institute of Research). WRNMMC was not subject to any FDA audit in February 2016. 
With this information in mind, we continue to appreciate the authors' willingness to contribute to the progression of science associated with neuropsychiatric diseases and treatments. However, the study findings must be viewed in the appropriate context, which includes the authors' omission of the study's ethical and regulatory challenges at WRNMMC.

\section{Disclosure}

The authors report no conflicts of interest in this communication.

\section{Reference}

1. Iosifescu DV, Neborsky RJ, Valuck RJ. The use of the Psychiatric Electroencephalography Evaluation Registry (PEER) to personalize pharmacotherapy. Neuropsychiatr Dis Treat. 2016;12:2131-2142. 


\section{Author's reply}

\section{Dan V losifescu, ${ }^{1,2}$ Robert J Neborsky, ${ }^{3-5}$ Robert J Valuck ${ }^{6-8}$}

'NYU School of Medicine, New York, NY, USA; ${ }^{2}$ Clinical Research, Nathan Kline Institute for Psychiatric Research Orangeburg, NY, USA; ${ }^{3}$ School of Medicine, University of California, San Diego, CA, USA; ${ }^{4}$ University of California, Los Angeles, CA, USA; ${ }^{5}$ Medical

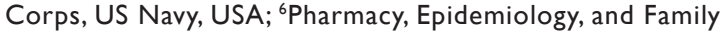
Medicine, University of Colorado, Denver, CO, USA; ${ }^{7}$ Center for Pharmaceutical Outcomes Research, University of Colorado, Denver, CO, USA; ${ }^{8}$ Colorado Consortium for Prescription Drug Abuse Prevention, Denver, CO, USA

Correspondence: Dan V losifescu

NYU School of Medicine, One Park Avenue, 8th Floor, New York, NY 10016

Tel + I $6467545 I 56$

Fax +I 2122637460

Email Dan.losifescu@nyumc.org

\section{Dear editor}

We welcome the opportunity to respond to the letter from Dr Weina and Mr Brooks regarding our paper "The use of the Psychiatric Electroencephalography Evaluation Register (PEER) to personalize pharmacotherapy", published in Neuropsychiatric Disease and Treatment. We find the description of the events as portrayed in the letter to omit relevant information, and we welcome the opportunity to set the record straight.

Our study, which was sponsored by the Department of Defense Medical Research Acquisition Activity and by CNS Response (the manufacturer of PEER Interactive), took place at Walter Reed National Military Medical Center (WRNMMC) and at Fort Belvoir (FBCH). The study was designed to enroll more than 1,000 subjects treated by military doctors for depression, and to compare the treatment outcomes of subjects whose treatment was guided by the EEG metric (PEER Interactive) versus treatment as usual. In February 2014 we performed a prespecified interim analysis of the data after enrolling the first $10 \%$ of the study sample. The Army shared the "promising early results" from our trial with the US Congress in April 2014. In essence, as shown in our paper, in comparison with treatment as usual, PEER-treated patients demonstrated superior treatment efficacy, including longer adherence with treatment and significantly superior reductions in suicidal ideation. Obviously, these results could also be interpreted as reflecting negatively on the modest efficacy of treatment as usual in the above-mentioned military centers.

The Defense Health Agency (DHA) was fully supportive of the PEER Interactive study until the early results emerged. However, in May 2014 the DHA suspended enrollment in the study shortly after we shared the preliminary analysis results, citing unspecified "subject safety and regulatory noncompliance" issues. In contrast, the Department of Defense reported to Congress in 2015 that "there were no quality or safety issues with the trial", and the DHA's own letter to study subjects in March 2015 said "Most significantly, there were NO concerns identified during the reviews regarding any clinical care that you have received as a result of your participation in the research project".

In January $2015 \mathrm{Mr}$ George Carpenter, CEO of the sponsor company CNS Response, now MyndAnalytics, was notified that the trial was halted by the DHA for unspecified "administrative reasons". The DHA refused to provide due process or provide any hearing on the evidence.

Although we could not understand the reasoning, we initially abided by the request from the WRNMMC and the DHA to not publish the results of the preliminary data analysis and we withdrew our accepted manuscript from Neuropsychiatric Disease and Treatment. However, we also requested a full investigation from the US Food and Drug Administration (FDA), which took place between February 3 and February 11, 2016. We would like to emphasize that the FDA team had full access to all the data collected at both study sites (WRNMMC and FBCH), as entered into the study electronic data capture system. In June 2016 the FDA response, which was sent to the DHA, Institutional Review Board and the sponsor, was very specific and cited the full title of our study, clearly stating that there were "no significant concerns" with the trial procedures or study data.

Having revalidated the study data with FDA oversight, the study team chose to publish the interim findings, despite the previous request from the DHA. It is our belief (and consistent with Department of Defense policies) that data from all clinical trials should be reviewed, published, and debated in the normal flow of scientific discourse. We would like to highlight that the interim results were reported and published in the journal only after several reviews of the data, including the full audit by the FDA, which "revealed no significant concerns", overruled in our opinion the claims used by the DHA to stop the project.

Out of an abundance of caution, we chose to add a section in our paper titled "Subsequent developments" where we summarized the controversy with DHA which held (and ultimately discontinued) the study, as well as the resolution after the FDA inspection. This "Subsequent developments" section, unusual for most papers, was included precisely in order to be fully transparent with regard to these events. 
Recently, new research programs to continue this protocol and to complete the clinical trial have started in the Veterans Administration and at another military site. Additionally, a replication trial is currently underway with Canadian Armed Forces. The continued interest of the military in testing PEER Interactive (although at different study sites) highlights the importance of this technology in potentially improving treatment efficacy and in reducing severe treatment side effects (including suicidal ideations).

\section{Disclosure}

The author reports no conflicts of interest in this communication.

Dove Medical Press encourages responsible, free and frank academic debate. The content of the Neuropsychiatric Disease and Treatment 'letters to the editor' section does not necessarily represent the views of Dove Medical Press, its officers, agents, employees, related entities or the Neuropsychiatric Disease and Treatment editors. While all reasonable steps have been taken to confirm the content of each letter, Dove Medical Press accepts no liability in respect of the content of any letter, nor is it responsible for the content and accuracy of any letter to the editor.

\section{Publish your work in this journal}

Neuropsychiatric Disease and Treatment is an international, peerreviewed journal of clinical therapeutics and pharmacology focusing on concise rapid reporting of clinical or pre-clinical studies on a range of neuropsychiatric and neurological disorders. This journal is indexed on PubMed Central, the 'PsycINFO' database and CAS, and is the official journal of The International Neuropsychiatric Association (INA). The manuscript management system is completely online and includes a very quick and fair peer-review system, which is all easy to use. Visit http://www.dovepress.com/testimonials.php to read real quotes from published authors. 